\title{
Cellular association and assembly of a multi-stage delivery system
}

\author{
Rita E. Serda ${ }^{*}, 1$, Aaron Mack ${ }^{1}$, Merlyn Pulikkathara ${ }^{1}$, Ana Maria Zaske ${ }^{2}$, Ciro Chiappini ${ }^{3}$, \\ Jean Fakhoury ${ }^{3}$, Douglas Webb ${ }^{4}$, Biana Godin ${ }^{1}$, Jodie L. Conyers ${ }^{2}$, XueWu Liu ${ }^{1}$, James A. \\ Bankson $^{3,4}$, and Mauro Ferrari ${ }^{*}, 1,5,6$ \\ 1 University of Texas Health Science Center (UTHSC), Department of Nanomedicine and \\ Biomedical Engineering, 1825 Pressler, Suite 537, Houston, TX 77030 \\ ${ }^{2}$ Center for Translational Injury Research, 6431 Fannin St., MSB 5.422, Houston, TX 77030 \\ ${ }^{3}$ University of Texas at Austin, Department of Biomedical Engineering, 1 University Station, \\ C0400, Austin, TX 78712 \\ ${ }^{4}$ University of Texas MD Anderson Cancer Center, Department of Imaging Physics, 1515 \\ Holcombe Blvd., Houston, TX 77030 \\ 5 University of Texas MD Anderson Cancer Center, Department of Experimental Therapeutics, \\ Unit 422, 1515 Holcombe Blvd., Houston, TX 77030 \\ ${ }^{6}$ Rice University, Department of Bioengineering, Houston, TX 77005
}

\section{Abstract}

The realization that blood-borne delivery systems must overcome a multiplicity of biological barriers has led to the fabrication of a multi-stage delivery system (MDS) designed to temporally release successive stages of particles or agents to conquer sequential barriers with a goal of enhancing delivery of therapeutic and diagnostic agents to the target site. In its simplest appearance, the MDS is comprised of stage one porous silicon microparticles that function as carriers of second stage nanoparticles. In this study, cellular uptake of non-targeted discoidal silicon microparticles by macrophages was confirmed by electron and atomic force microscopy (AFM). Using SPIONs as a model of secondary nanoparticles, successful loading of the porous matrix of silicon microparticles was achieved and retention of the nanoparticles was enhanced by aminosilylation of the loaded microparticle with 3-aminopropyltriethoxysilane. The impact of silane concentration and reaction time on the nature of the silane polymer on porous silicon was investigated by AFM and X-ray photoelectron microscopy. Tissue samples from mice intravenously administered the MDS supported co-localization of silicon microparticles and SPIONs across various tissues with enhanced SPION release in spleen, compared to liver and lungs, and enhanced retention of SPIONs following silane capping of the MDS. Phantom models of the SPION-loaded MDS displayed negative contrast in magnetic resonance images. In addition to forming a cap over the silicon pores, the silane polymer provided free amines for antibody conjugation to the microparticles, with both VEGFR-2 and PECAM specific antibodies leading to enhanced endothelial association. This study demonstrates assembly and cellular association of a multi-particle delivery system that is bio-molecularly targeted and has potential for applications in biological imaging.

\footnotetext{
*To whom correspondence should be addressed: Rita E. Serda and Mauro Ferrari, University of Texas Health Science Center, Department of NanoMedicine and Biomedical Engineering, 1825 Pressler Street, Suite 537, Houston, TX 77030, Phone: 713-500-2309; Rita.Serda@uth.tmc.edu; Mauro.Ferrari@uth.tmc.edu.
} 


\section{Keywords}

porous silicon; multi-stage; SPION; nanoparticle; microparticle

\section{Introduction}

While nanomedicine has made great strides in reaching the clinic with passively targeted liposomal doxorubicin [1-3] and taxane-loaded albumin nanoparticles [4], custom-designed nanoparticles that specifically target pathological lesions are still in the developmental stages. Achieving site-specific delivery of therapeutics and contrast agents is the key to eliminating undesirable systemic effects and enhancing imaging and therapeutic efficacy. In addition to targeting cancer cells, blood-borne delivery systems must overcome abundant and sequential biological barriers. To overcome these challenges, we have envisioned a multi-stage delivery system (MDS) comprised of stage 1 porous silicon microparticles (S1MP) loaded with one or more types of second stage nanoparticles that in turn either carry active agents or higher levels of nanoparticles [5]. Each level of complexity presents a solution for overcoming barriers, such as enzymatic degradation, negotiating vascular transport, crossing the vascular endothelium, and bypassing molecular efflux pumps. Employing methods of photolithography [6-7], porous silicon microparticles have been fabricated with precise control over particle geometry and size, factors that govern vascular navigation, cellular uptake, and tissue distribution of the particles [8-10]. The tunable pore size of the S1MPs permits optimization of the MDS for specific loads [6], as well as providing control over the rate of degradation [11-12]. The first level of targeting, which occurs in the blood vessel, is envisioned to be achieved at the level of the S1MP by attaching targeting moieties (e.g. peptides [13], antibodies [14], aptamers [15]) to the surface of the S1MP to direct interaction with tumor-associated endothelia lining the vessel wall.

One option for second stage nanoparticles are superparamagnetic iron oxide $\left(\mathrm{Fe}_{2} \mathrm{O}_{3} / \mathrm{Fe}_{3} \mathrm{O}_{4}\right)$ nanoparticles (SPIONs) [16-17]. SPIONs are excellent contrast agents for magnetic resonance (MR) imaging [14,18]. Toxicity testing of SPIONs in animals [19-20], and clinical use in humans [21], supports their use as safe and well tolerated. Accumulation of nanoparticles inside a protective first stage carrier may enhance delivery of a large number of nanoparticles to a common destination, decrease renal elimination of small nanoparticles, and allow for temporal release of the second stage particles. Additionally, transport in the silicon vector could potentially decrease the need for shielding of nanoparticles with polymers, such as poly(ethylene glycol) (PEG) [22-23], and enhance retention of nanoparticle surface coatings and targeting ligands.

In this study, we examine cellular uptake of discoidal S1MPs by scanning and transmission electron and atomic force microscopy. We present a bio-molecularly targeted MDS comprised of S1MPs encapsulating SPIONs within their porous matrix and examine intracellular localization of control and SPION loaded S1MPs in macrophages. The effect of 3-aminopropyltriethoxysilane (APTES) modification of the porous silicon surface on both loading and retention of SPIONs is studied, with a detailed account of the effects of time and silane concentration on the extent of polymerization of the silicon surface. Additionally, free amines present in the silane polymer provide anchors for attaching functional units and the impact of conjugating endothelial specific antibodies to the MDS surface on cellular association is studied by confocal microscopy and flow cytometry. The potential for MR imaging with the MDS is examined by comparing spin and gradient echo relaxation times in phantoms containing either S1MPs or the MDS. Lastly, the in vivo stability of the MDS is studied by administration of the MDS to mice and staining of harvested tissues with Prussian blue. 


\section{Results}

\subsection{J774A.1 Engulfment of S1MPs}

Cellular engulfment of discoidal S1MPs by J774A.1 macrophages was demonstrated by scanning electron and atomic force microscopy. Scanning electron micrographs show unique J774A. 1 cells at 10, 25, and 50 minutes after the introduction of S1MPs at $37^{\circ} \mathrm{C}$ (Figure 1.A). Cells were chosen as representative of the majority of cells at each time point and are not depicting the kinetics of uptake of specific microparticles. Early time points show little, if any extension of the cell membrane towards the microparticles. After 25 minutes, a cell is shown with one S1MP remaining on the cell surface, and a second S1MP completely covered by cell membrane. At 50 minutes, a cell is shown with a partially internalized S1MP on the cell surface while other microparticles may be completely internalized.

Confirmation of cellular uptake was obtained by imaging J774A.1 cells one hour after introduction of S1MPs by atomic force microscopy (AFM). Initial geometric analysis of S1MPs by AFM show S1MPs with an aspect ratio of 6.4 based on a measured length of 3.9 $\mu \mathrm{m}$ and an average height of $0.605 \mu \mathrm{m}$ (Figure 1.B). An atomic force micrograph of a J774A. 1 cell reveals a cell diameter of $21.5 \mu \mathrm{m}$, nucleus $13.5 \mu \mathrm{m}$, and an internalized S1MP with a measured diameter of $3.2 \mu \mathrm{m}$ (Figure 1.C). Based on cellular topography it is likely that multiple S1MPs are colocalized within the cell. This data supports cellular uptake of discoidal S1MPs by macrophages.

\subsection{Loading S1MPs with SPIONs}

Discoidal S1MPs were fabricated by our group using standard photolithography and plasma etching. S1MPs with a diameter of $3.2 \pm 0.2 \mu \mathrm{m}$ (based on SEM analysis) and pore size of $51.3 \pm 28.7 \mathrm{~nm}$ were chosen to study the effect of silicon surface modification on loading of the porous matrix with secondary nanoparticles. Scanning electron micrographs were taken at increasing magnification to illustrate S1MP shape and relative pore size (Figure 2.A). Ultrathin sections of S1MPs are also presented in transmission electron micrographs in a series of increasing magnification images (Figure 2.B).

Loading of oxidized S1MPs with amine modified $10 \pm 2.5 \mathrm{~nm}$ SPIONs was compared to loading aminosilylated S1MPs with carboxylated SPIONs. Silane polymerization (i.e. APTES modification) was carried out for 18 hours using a 9\% (v/v) APTES solution in IPA. Loading of the porous silicon matrix was by the incipient wetness method, with retention based on electrostatic interactions. Based on transmission electron micrographs, the silane polymer blocked nanoparticle access to the pores (Figure 2.C). Conversely, the pores of oxidized S1MPs were freely penetrated by SPIONs. High resolution scanning transmission electron microscopy (STEM) images confirmed the presence of SPIONs throughout the porous matrix of the oxidized S1MPs (Figure 2.D).

\subsection{High resolution scanning electron microscopy (SEM)}

To further characterize loading of S1MPs with SPIONs, loaded microparticles were imaged using a high resolution Hitachi S-5500 SEM (Figure 3.A\&B). Micrographs, taken at increasing magnification, show $10 \mathrm{~nm}$ SPIONs within the porous matrix in close proximity to silicon surfaces (Figure 3.A). Larger SPIONs $(30 \mathrm{~nm}$ ) were similarly loaded and were abundant within the porous silicon matrix (Figure 3.B).

\subsection{Magnetic resonance (MR) imaging of the MDS}

MR imaging of SPION samples was carried out in an actively-shielded 7 Tesla Biospec USR70/30 (Bruker Biospin MRI, Billerica, MA) small animal MRI system equipped with a $30-\mathrm{cm}$ bore, $6-\mathrm{cm}$ gradients $(950 \mathrm{mT} / \mathrm{m})$, and a linear ${ }^{1} \mathrm{H}$ birdcage-style volume resonator 
with $35 \mathrm{~mm}$ inner diameter. S1MPs $\left(5 \times 10^{6}\right)$, control or loaded in the presence of either 10 $\mu \mathrm{g}\left(\mathrm{MDS}_{\mathrm{lo}}\right)$ or $50 \mu \mathrm{g}\left(\mathrm{MDS}_{\mathrm{hi}}\right)$ of SPIONs (10 $\mathrm{nm}$ core) were suspended in phosphate buffered saline (PBS) alongside pure PBS (blank) in NMR tubes, which were all suspended in water in a specially machined tube holder. The transverse signal relaxation time constant $\left(\mathrm{T}_{2}\right)$ of each sample was measured using a Carr-Purcell-Meiboom-Gill echo train (minimum $\mathrm{TE}=15 \mathrm{~ms}$, echo spacing $15 \mathrm{~ms}, 24$ echoes, $\mathrm{TR}=1100 \mathrm{~ms}$ ). Effects on transverse relaxation time $\left(\mathrm{T}_{2}{ }^{*}\right)$ due to susceptibility of SPION was measured using a multi-gradient echo sequence $\left(\right.$ minimum TE $=1.5 \mathrm{~ms}$, echo spacing $=3.25 \mathrm{~ms}, 16$ echoes, $\mathrm{TR}=4000 \mathrm{~ms}, 30^{\circ}$ excitation). Figure $3 \mathrm{C}$ shows axial $\mathrm{T}_{2}$-weighted fast spin-echo $\mathrm{MR}$ images $(\mathrm{TE}=65 \mathrm{~ms}$, TR $=5000 \mathrm{~ms}, \mathrm{ETL}=12$, and NEX $=3$ ) of phantoms containing either unloaded S1MPs or MDS. Longer $T_{2}$ for the blank and S1MPs (107 and $88 \mathrm{~ms}$, respectively) result in significantly less negative contrast than for $\mathrm{MDS}_{\mathrm{lo}}(\mathrm{T} 2=49)$ and $\mathrm{MDS}_{\mathrm{hi}}(\mathrm{T} 2=38 \mathrm{~ms})$ in $\mathrm{T}_{2}-$ weighted spin-echo images. Differences in signal intensity are more dramatic at lower echo times in gradient-echo images, as shown in Figure 3D $\left(\mathrm{TE}=14.5 \mathrm{~ms}, \mathrm{TR}=4000 \mathrm{~ms}, 30^{\circ}\right.$ excitation). In agreement with $\mathrm{T} 2$ values, $\mathrm{T} 2 *$ for the blank and S1MP are significantly longer than for the $\mathrm{MDS}_{\mathrm{lo}}$ and $\mathrm{MDS}_{\mathrm{hi}}$.

\subsection{Intracellular trafficking of SPION loaded S1MPs (MDS)}

To determine the intracellular fate of S1MPs and MDS we incubated J774A.1 macrophages with ten MDS per cell for 24 hours at $37^{\circ} \mathrm{C}$. Three internalized S1MPs, in different orientations, are shown in Figure 4.A (boxes). Higher magnification images of the three boxed S1MPs are shown to the right. A cell with 2 MDS is shown in Figure 4B, with higher magnification images of the MDS shown to the right. Clusters of S1MP-released $10 \mathrm{~nm}$ SPIONs (black arrows) are indicated in the high magnification images. Vesicular membranes surrounding unloaded S1MPs are tightly associated with the microparticles (S1MPs). In contrast, membranes surrounding MDS appear to "relax" or expand in the presence of the released SPIONs. The intracellular fate of the S1MP-released SPIONs and the impact of nanoparticle surface coating are under investigation.

\subsection{Characterization of APTES polymerization on porous silicon}

AFM was used to compare the roughness and surface height of an oxidized porous silicon wafer (Figure 5.A) with that of an APTES modified wafer (Figure 5.B). Piranha oxidized porous silicon wafers were incubated with $0.5 \%$ APTES (v/v) for 4 hours at room temperature. Silane polymerization increased the height of the surface features from 0.689 $\mathrm{nm}$ to $3.843 \mathrm{~nm}$.

Elemental analysis of the modified silane surface by X-ray Photoelectron Spectroscopy (XPS) demonstrated similar amounts of nitrogen on the aminosilylated surfaces at 2 hours, regardless of the concentration of APTES present in solution (Figure 5.C). After 4 hours incubation, the atomic percent of nitrogen was significantly greater in the 9\% APTES sample compared to the $2 \%(\mathrm{p}<0.02)$ sample. A similarly significant increase in atomic percent nitrogen was present in the 9\% APTES sample after 22 hours, compared to both the $0.5 \%(\mathrm{p}<0.0004)$ and the $2 \%(\mathrm{p}<0.009)$ samples. The increase in incubation time from 2 to 4 hours did not significantly increase the atomic percent nitrogen on the silicon surface, but extended incubation at 22 hours significantly increases the atomic percent nitrogen for the $0.5 \%(\mathrm{p}<0.02$ and $9 \%(\mathrm{p}<0.002)$ APTES samples. The increase in atomic percent nitrogen directly corresponds to an increase in polymer thickness. Surface roughness, caused by an inhomogeneous layer across the surface, was also positively correlated with incubation time, as shown in Figure 5.F. The roughness of the silicon surface increased significantly with each increase in incubation time ( 0 vs 2 hours, $\mathrm{p}<0.0005 ; 2$ vs 4 hours, $\mathrm{p}<0.0001 ; 4$ vs 22 hours, $p<0.002$ ). The combined increase in surface height, atomic percent nitrogen, and surface roughness with time and APTES concentration indicates the presence of an 
extensive polymer coat surrounding the porous silicon matrix after 22 hours incubation in $9 \%$ APTES (v/v).

\subsection{Quantification of SPION load in S1MPs}

S1MPs were loaded with increasing concentrations of SPIONs, and a nonlinear fit of the data was performed using Graph Pad Prism $\left(\mathrm{R}^{2}=0.8029\right.$; Figure 6.A). SPION loading and retention within S1MPs increased linearly with concentrations ranging from $0.01-5 \mathrm{mg} / \mathrm{ml}$ iron (borate buffer, $\mathrm{pH} 5.0$ ), after which a plateau was reached. The amount bound represents the amount of iron present in $3 \times 10^{6} \mathrm{~S} 1 \mathrm{MPs}$. Loading efficiency, based on loading $1 \times 10^{7} \mathrm{~S} 1 \mathrm{MPs}$ in the presence of $1 \mathrm{mg} / \mathrm{ml}$ of iron (10 $\mu \mathrm{g} ; 10 \mathrm{~nm}$ SPIONs) was $19 \%$; however, this was based on Prussian Blue analysis of unbound and bound SPIONs, which only accounted for $20 \%$ of the original iron.

Having previously observed capping of the porous silicon matrix by a multilayer silane polymer during the loading process, the ability of the silane polymer to trap SPIONs within the porous matrix of oxidized S1MPs was evaluated (Figure 6.B). S1MPs were loaded with SPIONs and retention within the pores by electrostatic forces was compared to retention of SPIONs following APTES polymerization for varying lengths of time using a 9\% (v/v) APTES solution. Association of SPIONs with S1MPs was more than double (224\%) following overnight incubation with APTES, perhaps due to both enhanced retention and entrapment of SPIONs in the dense silane polymer. The zeta potential of all particle formulations, measured in $4 \mathrm{mM}$ sodium acetate ( $\mathrm{pH}$ 6.5), is displayed in Table 1.

\subsection{Scanning Transmission Electron Microscopy/Energy Dispersive X-ray Spectroscopy}

To confirm the presence of SPIONs in the porous silicon matrix following loading and capping, S1MPs were loaded with SPIONs, then sectioned with a microtome into ultra-thin slices (70nm) and analyzed by High Angle Annular Dark Field-Scanning Transmission Electron Microscopy (HAADF-STEM) combined with elemental maps from Energy Dispersive X-ray Spectroscopy (EDX) using a FEI TECNAI G2 F20 X-TWIN TEM at an accelerating voltage of $200 \mathrm{kV}$ (Figure 6.C). EDX elemental analysis was performed on the boxed region of the loaded S1MP. The presence of silicon (Si-K) and oxygen (O-K) was verified, as well as co-localization with the iron signal ( $\mathrm{Fe}-\mathrm{K}$ and $\mathrm{Fe}-\mathrm{L}$ ) originating from the loaded SPIONs. The spectrum in Figure 6.D. is a representative elemental analysis of the boxed region.

\subsection{S1MP degradation and release of SPIONs}

SPION-loaded S1MPs (MDS), in the presence and absence of an APTES cap, were incubated on a rotator at $25^{\circ} \mathrm{C}$ for 23 hours in phosphate buffered saline (PBS) and dissolution of the silicon particles was determined at various time points by Inductively Coupled Plasma Optical Emission Spectroscopy (ICP-OES) analysis of the supernatant (Figure 6.D). No degradation was detected at 1 and 2 hours. After 4 hours, silicon particles, capped and not capped, were $94 \%$ and $87 \%$ intact, respectively, but this decreased to $83 \%$ and $80 \%$ at 8 hours, and $46 \%$ for both groups at 23 hours. These data support greater than $50 \%$ degradation of the silicon particles at 23 hours in the presence of PBS at room temperature. Aminosilylation of the loaded S1MP did not alter the rate of degradation. In a separate experiment, using quasi-hemispherical S1MPs, degradation of SPION-loaded S1MPs and release of iron were monitored by measuring iron and silicon content in filtered $(0.45 \mu \mathrm{m})$ supernantant following incubation of the MDS in fetal bovine serum (FBS) at $37^{\circ} \mathrm{C}$, with sample rotation (supplemental Figure 1). Under these conditions, silicon degradation was more rapid, with $31 \%$ S1MP degradation at 4 hours and $96 \%$ degradation at 24 hours. SPION release paralleled S1MP degradation at most time points, with the exception of greater release (54\%), compared to degradation (31\%), at 4 hours. Degradation 
of porous silicon particles is very rapid in PBS and serum, with both release of SPIONs and degradation being greater than $50 \%$ at 24 hours under all conditions tested. However, in the presence of diverse bio-physical conditions, such as cellular uptake and acidic endosomal encapsulation, in vivo particle degradation is much slower (see section 2.11).

\subsection{MTT proliferation assay}

Viability of J774A.1 cells in the presence of each particle presentation was measured using a 3-(4,5-dimethylthiazol-2-yl)-2,5-diphenyltetrazolium bromide (MTT) proliferation assay at 24-96 hours (Figure 6.E). No significant differences in cell growth were measured for any group across all time points.

\subsection{In vivo stability of the MDS}

The impact of capping the MDS through aminosilyation on the in vivo stability of the assembled construct was tested by injecting mice (tail-vein) with either control, unloaded S1MPs or S1MPs loaded with SPIONs in the absence and presence of the silane cap. Tissues were harvested at 2 and 24 hours after particle introduction and sections from the lungs, liver, and spleen were stained with Prussian blue and Nuclear Fast Red to visualize SPIONs. In all spleen samples, iron was loosely associated with S1MPs (Figure 6.F). In the liver and lungs, uncapped and capped MDS displayed overlap of S1MPs and iron staining at 2 hours, indicating that the MDS was intact. After 24 hours, S1MPs were intact and association with SPIONs was evident, however, in the absence of the silane cap SPIONs appeared to be migrating away from the uncapped S1MPs. These data support enhanced retention of SPIONs in first stage porous silicon particles following silane capping. Control, unloaded S1MPs were negative for iron staining (not shown).

\subsection{In vitro targeting of the MDS with endothelial specific antibodies}

To enhance cell specific association of the MDS with vascular endothelial cells, either antiVEGFR-2 or PECAM antibody was covalently conjugated to the MDS surface following nanoparticle loading and APTES capping. Figure 7.A-C are confocal micrographs of IgG isotype control (A) and anti-VEGFR-2 (B,C) antibody labeled MDS and their association with Human Umbilical Vein Endothelial Cells (HUVECs). While the control IgG labeled MDS were predominantly independent of the cells, anti-VEGFR-2 antibody labeled MDS were found in association with endothelial cells. To determine if the targeted MDS particles were internalized by HUVECs, a z-stack of a magnified cell is shown in Figure 7.C (center image). The actin cytoskeleton, stained with Rhodamine Phalloidan, lies beneath the MDS, indicating surface attachment. The far right image in Figure 7.C shows two adjacent endothelial cells with MDS units located among extended lamellopodia. Fluorescein conjugated antibodies were used in the study for imaging and to quantify bound antibody by flow cytometric analysis. The number of antibody molecules bound per MDS was calculated based on a standard curve created using Quantum ${ }^{\mathrm{TM}}$ Simply Cellular ${ }^{\circledR}$ anti-Mouse IgG beads. Analysis of isotype control or anti-VEGFR-2 antibody labeled particles indicated that each particle had approximately 17,000 antibody molecules on its surface (Figure 7.D).

Endothelial specific association of the targeted MDS was quantitated across two endothelial cell lines, HUVECs and Human Microvascular Endothelial Cells (HMVECs) using control $\mathrm{IgG}$ and anti-PECAM antibody labeled MDS. Binding was quantified by measuring the percent of cells with high side scatter (minus side scatter from control cells). HUVEC and HMVEC cells associated significantly more with anti-PECAM labeled MDS as compared to control IgG labeled MDS, displaying an 8.8-fold $(\mathrm{p}<0.03)$ and 1.7-fold $(\mathrm{p}<0.004)$, respectively, enhancement in binding in the presence of endothelial specific antibody. 


\section{Discussion}

In this study, assembly of a multi-particle MDS with targeting and potential imaging capabilities was demonstrated. The first stage porous silicon carriers, S1MPs, are biodegradable and bio-functional due to porosification and oxidation, respectively. The S1MPs are mathematically designed to possess geometric properties that both enhance vascular migration and manipulate cellular uptake [24]. Herein we show that S1MPs are internalized by J774A.1 mouse macrophages. Scanning electron micrographs demonstrate multiple stages of S1MP uptake and optimal particle orientation for cellular uptake (i.e. maximal surface-to-surface contact). Internalization of S1MPs was further supported by atomic force micrographs that supported the presence of S1MPs beneath the cell surface. As reported by others, phagocytic blood monocytes/macrophages migrate to sites of inflammation [25], and have been reported to serve as carriers for particles to inflamed and necrotic regions [26-27], such as that found in tumor tissue. Thus cellular uptake of delivery vectors by monocytes/macrophages may provide a means for delivering non-targeted MDS to cancer lesions.

Overnight incubation of oxidized S1MPs with 9\% (v/v) APTES created a multi-layer silane polymer that interfered with SPION loading. However, the hydrophilic, negatively charged surface of oxidized S1MPs permitted association with SPIONs. Following loading, high resolution STEM and SEM images show large numbers of SPIONS throughout the porous matrix. SPIONs adhere to the silicon surface, simultaneously coating the pores and concentrating the SPIONs within the S1MPs. Delivery of a single MDS to a cell would constitute delivery of a multitude of nanoparticles, which should enhance both cell tracking and therapeutic efficacy for drug loaded nanoparticles. Phantom models containing the MDS shortened $\mathrm{T} 2$ and $\mathrm{T} 2 *$ relaxation times in a manner dependent on SPION concentration. $\mathrm{MDS}_{\mathrm{lo}}$ MRI phantoms contained $5 \times 10^{6}$ MDS in $600 \mu \mathrm{l}$ of PBS (14 femtomolar iron based on $100 \%$ loading efficiency). The mice in this study were injected with $1 \times 10^{8} \mathrm{MDS}$ in 100 $\mu \mathrm{l}$ of PBS, corresponding to a dose 120 times more concentrated than the MRI phantom, with 20 times the dose of particles. The in vivo detection threshold for SPIONs is reported to be femtomole quantities, with several studies reporting MRI detection of a few hundred SPION-labeled cells [28].

Transmission electron micrographs of non-capped, loaded MDS following internalization by macrophages show SPIONs being released from S1MPs 24 hours after internalization. The SPIONs are clustered and appear to be actively sorted to specific regions of the vesicles. The appearance of multiple vesicular bodies within the phagosomal units, and the possible sorting of its contents are indicative of activities found in sorting endosomes [29]. The final subcellular destination and the impact of second stage nanoparticle (i.e. SPION) surface coating and size on intracellular trafficking are under investigation.

Blockade of loading the porous silicon matrix with SPIONs by aminosilylation led us to study the impact of silane concentration and reaction time on the resulting silane polymer. Modification of the oxidized porous silicon surface with APTES at both increasing concentration and incubation time positively correlated with an increase in surface height, atomic percent nitrogen, and surface roughness of the silicon surface, as previously reported by others [30]. Multiple layers of cross linked silane molecules contribute to the increased surface height [31]. Based on the extensive coating (i.e. capping) of the porous silicon matrix following overnight incubation with APTES, oxidized S1MPs were first loaded with SPIONs, and then capped by aminosilylation of the particle surface. Aminosilylation of the loaded S1MPs for 2-4 hours did not alter the amount of loaded SPIONs, however, extension of the reaction time to 16 hours, more than doubled the amount of SPIONS associated with S1MPs. It is believed that the extensive polymer coat may both prolong retention of SPIONs 
within the porous matrix and induce capture of additional SPIONS within the multi-layer polymer coat. Confirmation of loading and retention of SPIONs within the S1MP pores during the APTES capping procedure comes from HAADF-STEM images and EDX elemental mapping of particles within the pores.

Cellular compatibility of the loaded and capped particles was supported by in vitro proliferation assays which demonstrated similar cellular proliferation following incubation with all particle formulations. Previously we reported a similar lack of cytotoxicity for endothelial cells incubated with SPION or gold nanoparticle conjugated S1MPs[32]. Enhanced in vivo retention of SPIONs in capped MDS was supported by intravascular injection of the MDS into mice and subsequent colocalization of S1MPs and iron by histological analysis of lung, liver and spleen. These tissues were selected based on earlier findings by our group showing preferential localization of non-targeted discoidal silicon microparticles in the tissues[33].

In vitro degradation studies indicated that $54 \%$ of the silicon content from SPION loaded S1MPs is released into solution after incubation in PBS for 23 hours at $25^{\circ} \mathrm{C}$ with motion. The presence of surface aminosilylation on loaded S1MPs did not impact the degradation rate. Conversely, transmission electron micrographs of macrophages with internalized MDS at 24 hours did not support high levels of S1MP degradation, perhaps due to confinement of the particles within acidic vesicular compartments. Rapid cell-free degradation of S1MPs at $37^{\circ} \mathrm{C}$ in FBS and a parallel release of SPIONs supports a release mechanism that is driven predominately by the rate of S1MP degradation under cell-free conditions; however, intracellular release and trafficking of SPIONs is more complex and is currently under investigation.

In addition to particle "capping", aminosilylation of loaded S1MPs provided substrates for attachment of endothelial specific antibody. Preliminary in vitro studies supported enhanced endothelial association with anti-VEGFR-2 and anti-PECAM antibody conjugated MDS, compared to isotype control IgG labeled MDS, in the presence of serum across two endothelial subtypes, HUVEC and HMVEC.

\section{Conclusions}

This study demonstrates assembly of a targeted, multi-stage (multi-particle) delivery system with potential as a contrast agent for MR imaging by entrapment of SPIONs in a porous silicon matrix.

\section{Experimental methods}

\subsection{Porous silicon microparticle fabrication}

Porous silicon particles were fabricated in the Microelectronics Research Center at The University of Texas at Austin. Silicon particles, featuring a mean diameter of $3.2 \pm 0.2 \mu \mathrm{m}$ and an average pore size of $51.3 \mathrm{~nm}$, were fabricated by modification of protocols recently published by our laboratory [6]. Briefly, heavily doped p++ type (100) silicon wafers with resistivity of $0.005 \mathrm{ohm}-\mathrm{cm}$ (Silicon Quest, Inc, Santa Clara, CA) were used as the silicon source. A $40 \mathrm{~nm} \mathrm{SiO}_{2}$ layer was thermally grown on the wafer at $950 \mathrm{C}$, followed by an 80 nm layer of silicon nitride ( $\mathrm{SiN}$ ) deposited by Low Pressure Chemical Vapor Deposition. Standard photolithography was used to pattern a $2 \mu \mathrm{m}$ circular pattern with $2 \mu \mathrm{m}$ pitch over the wafer using a contact aligner (K. Suss MA6 mask aligner) and PR-1000A photoresist (Futurrex Franklin, NJ, USA). The pattern was transferred into the SiN by dry etch in $\mathrm{CF}_{4}$ plasma (Plasmatherm 790, 25sccm CF 4,100 mTorr, 200W RF, 2'), and into the $\mathrm{SiO}_{2}$ by wet etch in $5 \% \mathrm{HF}$ for $1^{\prime} 30^{\prime \prime}$ to prevent overetch into the silicon. The silicon particles with both 
mechanical stability and high porosity were then formed by a three-step electrochemical etch in 1:3 HF:Ethanol solution. An initial low porosity layer of approximately $20 \mathrm{~nm}$ was formed by applying a $10 \mathrm{~mA} \mathrm{~cm} \mathrm{c}^{-2}$ current for $10^{\prime \prime}$. The electrical current was then smoothly increased to $100 \mathrm{~mA} \mathrm{~cm}^{-2}$ over the course of $15^{\prime \prime}$ forming a $70 \mathrm{~nm}$ thick layer of transition between low porosity and high porosity, and the $100 \mathrm{~mA} \mathrm{~cm}{ }^{-2}$ current was applied for 30' forming a $600 \mathrm{~nm}$ porous layer. Finally a $380 \mathrm{~mA} \mathrm{~cm}^{-2}$ current was applied for 6 " forming a release layer. The masking $\mathrm{SiN}$ and $\mathrm{SiO}_{2}$ layers were removed in $49 \% \mathrm{HF}$, and the silicon particles released form the substrate by sonication in isopropanol. Quasi-hemispherical S1MPs had a mean particle diameter of $3.2 \pm 0.2 \mu \mathrm{m}$, with an average pore size of $26.3 \mathrm{~nm}$. Processing details were recently published by our laboratory [6].

\subsection{Surface modification of porous silicon microparticles}

The IPA suspension containing S1MPs was transferred to a glass beaker and the IPA was evaporated using a hotplate set at $110^{\circ} \mathrm{C}$ overnight. The dried S1MPs were then treated with piranha solution ( 1 volume $\mathrm{H}_{2} \mathrm{O}_{2}$ and 2 volumes of $\mathrm{H}_{2} \mathrm{SO}_{4}$ ) with heating to 110-120 0C for 2 hours with intermittent sonication to disperse the S1MPs. The suspension was then washed in deionized (DI) water until the $\mathrm{pH}$ of the suspension was higher than 5.5.

Oxidized S1MPs were washed in IPA 3-4 times, and then suspended in IPA containing 0.5-9\% (v/v) APTES (Sigma-Aldrich, St. Louis, MO) for 0.5-22 hour at $35^{\circ} \mathrm{C}$ and $1300 \mathrm{rpm}$. The APTES modified S1MPs were washed in IPA and surface charge was evaluated by zeta potential analysis.

\subsection{Atomic force microscopy}

J774A.1 cells, grown on collagen-coated glass coverslips, were treated with S1MPs in DMEM containing $10 \% \mathrm{FCS}$ and antibiotics for 60 minutes at $37^{\circ} \mathrm{C}$ at a cell to particle ratio of 1:5. Cells were fixed in $4 \%$ formaldehyde overnight at $4^{\circ} \mathrm{C}$, washed with nano-pure water and let dry over a sterilGARD III hood flow prior imaging. Atomic Force Microscopy (AFM) was conducted using a Veeco di BioScope II ${ }^{\mathrm{TM}}$ integrated with a Nikon TE2000 inverted optical microscope. Scanning was performed using tapping mode in air and RTESP cantilevers ( $\mathrm{fo}=262-325 \mathrm{kHz}, \mathrm{k}=20-80 \mathrm{~N} / \mathrm{m}$ ). Image analysis was performed with the Research NanoScope software version 7.30.

For AFM imaging of oxidized verses APTES modified porous silicon, continuous porous layers were formed on silicon wafers by electrochemical etch using the same parameters described for silicon microparticles. The surface of the wafer was evaluated for height and roughness using a Veeco Nanoscope III (Digital Instruments) in tapping mode in air and TESP cantilevers (fo $=320 \mathrm{kHz}, \mathrm{k}=42 \mathrm{~N} / \mathrm{m}$ ).

\subsection{X-ray photoelectron spectroscopy}

Elemental analysis and evaluation of chemical bonding on the modified silicon wafers were performed using a PHI Quantera X-ray Photoelectron Spectrometer (XPS) equipped with a monochromatic $\mathrm{Al} \mathrm{K} \alpha$ radiation source $(1486.6 \mathrm{eV})$ with a power setting of $350 \mathrm{~W}$ and analyzer pass energy of $69.0 \mathrm{eV}$.

\subsection{Loading S1MPs}

Aliquots containing $3-5 \times 10^{6}$ oxidized (negative) or APTES ( $\left.9 \%(\mathrm{v} / \mathrm{v}), 22 \mathrm{hrs}\right)$ modified (positive) S1MPs were dried overnight either by thermal heating at $37^{\circ} \mathrm{C}$ or at room temperature in a vacuum desiccator. Favorably charged SPIONs (amine or carboxy modified, respectively; $\mathrm{Fe}_{3} \mathrm{O}_{4} / \mathrm{Fe}_{2} \mathrm{O}_{3} ; 10-15$ or $30 \mathrm{~nm}$; purchased from Ocean NanoTech, LLC. Springdale, AR) were added to the dry S1MPs at concentrations of ranging from 0.1-5 $\mathrm{mg} / \mathrm{ml}$ in a total volume of $10-25 \mu \mathrm{l}$. Borate buffer was used for loading by the incipient 
wetness method [34-36] (0.01 M, pH 5.0 for amine modified SPIONs, and $50 \mathrm{mM}$, pH 8.5 for carboxylic acid modified SPIONs). For loading, particles were briefly sonicated, then incubated at room temperature with agitation $(1300 \mathrm{rpm})$ for $10 \mathrm{~min}$ followed by no motion for $20 \mathrm{~min}$. Samples were then centrifuged at $4200 \mathrm{rpm}$ (Beckman Coulter Allegra X-22 Centrifuge equipped with a 296/06 rotor) for 5-10 minutes and the pellet was washed with $50 \mu \mathrm{l}$ water to remove free iron oxide. For STEM and TEM imaging, the loaded S1MPs were suspended in $2 \%$ agarose, cut into $1 \mathrm{~mm}$ slices, and suspended in water. Samples were then dehydrated with a series of increasing ethanol concentrations $(50,70,95,100 \%)$ with the final dehydration step at $100 \%$ repeated twice ( $20 \mathrm{~min}$ per step), followed by two washes in $100 \%$ acetone. The samples were then infiltrated with Spurr's resin at the following concentrations of resin to acetone: 1:2, 2:1, and 1:0 for 2-4 hours for each condition. The samples were then embedded in fresh Spurr's resin, with polymerization performed at $70^{\circ} \mathrm{C}$ for 8 hours. For high resolution SEM imaging of the loaded S1MPs, washed samples were resuspended in $50 \mu \mathrm{l}$ water and an aliquot was dried on an SEM specimen stub. Samples were imaged using a Hitachi S-5500 at $30 \mathrm{kv}$.

\subsection{Entrapment and quantification of SPIONs}

For APTES capping of the porous silicon matrix post-loading, oxidized S1MPs $\left(5 \times 10^{6}\right)$ were loaded with SPIONs ( $25 \mu \mathrm{g}$; amine modified) in $25 \mu \mathrm{l}$ borate buffer, then centrifuged and washed twice in fresh borate buffer. Loaded S1MPs were then resuspended in a 9\% (v/ v) APTES solution in IPA $(50 \mu \mathrm{l})$ for $0.5,4$, or 16 hours in a thermomixer at $23^{\circ} \mathrm{C}$ at 1300 RPM. The particles were then washed twice in IPA and resuspended in a final volume of 50 $\mu$ l. Iron oxide loading and entrapment (i.e. "capping") were quantitated using a Prussian Blue iron assay [14]. An aliquot from each sample $(5 \mu \mathrm{l})$ was heated at $50^{\circ} \mathrm{C}$ in $120 \mu \mathrm{l} 6 \mathrm{~N}$ $\mathrm{HCl}$ for 2 hours with agitation to convert SPIONs into free iron. Iron was then oxidized using $0.1 \mathrm{mg} / \mathrm{ml}$ ammonium persulfate (BioRad, Richmond, $\mathrm{CA}$ ) and the color reaction was initiated by adding $125 \mu \mathrm{l}$ of a $5 \% \mathrm{~K}_{4}\left[\mathrm{Fe}(\mathrm{CN})_{6}\right] \cdot 3 \mathrm{H}_{2} \mathrm{O}$ (Sigma-Aldrich) for $10 \mathrm{~min}$. A standard curve was generated using iron III hexahydrate (Sigma-Aldrich), and absorbance was read at $690 \mathrm{~nm}$ using a Molecular Devices M5 plate reader spectrophotometer.

\subsection{MRI phantoms}

MR phantoms were prepared in 5mm thin wall NMR tubes (Wilmad Labglass, Vineland, NJ) using S1MPs $\left(5 \times 10^{6}\right)$ loaded with either 10 or $50 \mu \mathrm{l}$ of $10 \mathrm{~nm}$ SPIONs $(1 \mathrm{mg} / \mathrm{ml})$ suspended in $600 \mu \mathrm{L}$ of PBS. Sample sets of 4-5 phantoms, including a PBS only control, were moved into a specially machined tube holder which was placed into a $50 \mathrm{~mL}$ centrifuge tube. The tube was then filled with water to reduce interference from air interfaces, doped with $0.1 \%$ Magnevist (v/v), capped, and imaged. Characteristic transverse relaxation times, $\mathrm{T}_{2}$ and $\mathrm{T}_{2}{ }^{*}$, were measured using spin-echo and multiple gradient-echo sequences as specified in the results section.

\subsection{Electron microscopy}

5.8.1 Scanning transmission electron microscopy/energy dispersive x-ray spectroscopy-S1MPs loaded with SPIONs were cut into ultrathin sections using a microtome (Leica, Deerfield, IL) and analyzed by High Angle Annular Dark Field Scanning Transmission Electron Microscopy (HAADF-STEM) combined with elemental maps from Energy Dispersive X-ray Spectroscopy (EDX) using a FEI TECNAI G2 F20 XTWIN TEM at an accelerating voltage of $200 \mathrm{kV}$, set at nanoprobe spot mode \#7, and tilted at an angle of $12^{\circ}$. The EDX spectrum was sampled in 225 spots on a $15 \times 15$ grid (see box in Figure 6.D), with a dwell time of $8000 \mathrm{~ms}$ per spot. 
5.8.2 Scanning electron microscopy-For particle imaging, S1MPs, suspended in either IPA or water, were dried on ethanol washed SEM stubs (Ted Pella, Inc.) overnight in a desiccator. For cell-based imaging, J774A.1 murine macrophage cells, purchased from American Type Culture Collection (Manassas, VA), were cultured in Dulbecco's Modified Eagle's Medium containing 10\% FBS, $100 \mu \mathrm{g} / \mathrm{ml}$ streptomycin and $100 \mathrm{U} / \mathrm{ml}$ Penicillin (Invitrogen; Carlsbad, CA). J774A.1 cells were plated in a 24 well plate containing $5 \times 7$ mm Silicon Chip Specimen Supports (Ted Pella, Inc., Redding, CA) at $7.5 \times 10^{4}$ cells per well. Twenty-two hours later, media containing S1MPs (1:5, cell:microparticles, $0.5 \mathrm{ml} /$ well) was introduced and cells were incubated at $37^{\circ} \mathrm{C}$ for 1025 , or $50 \mathrm{~min}$. Samples were fixed in $2.5 \%$ glutaraldehyde for $30 \mathrm{~min}$ (Sigma-Aldrich; St. Louis, MO), then dehydrated in increasing concentrations of ethanol, followed by incubation in a 50\% alcoholhexamethyldisilazane (Sigma) solution for $10 \mathrm{~min}$, with a final incubation in pure HMDS for $5 \mathrm{~min}$ to prepare for overnight drying in a desiccator. Specimens were mounted on SEM stubs (Ted Pella, Inc.) using conductive adhesive tape (12mm OD PELCO Tabs, Ted Pella, Inc.). Samples were sputter coated with a $10 \mathrm{~nm}$ layer of gold using a Plasma Sciences CrC-150 Sputtering System (Torr International, Inc.). SEM images were acquired under high vacuum, at $20.00 \mathrm{kV}$, spot size 5.0, using a FEI Quanta 400 FEG ESEM equipped with an ETD (SE) detector. High resolution images

5.8.3 Transmission electron microscopy-J774A.1 cells were plated at $2 \times 10^{5}$ cells per well in a 6 well cell culture plate. Twenty-two hours later, S1MPs, loaded and control unloaded, were introduced at a cell:microparticle ratio of $1: 5$ at $37^{\circ} \mathrm{C}$ for 24 hours. Cells were then washed and fixed in a solution of $2 \%$ paraformaldehyde (Electron Microscopy Sciences; Hatfield, PA) and 3\% glutaraldehyde (Sigma-Aldrich) in PBS, pH 7.4 for one hour at room temperature. After fixation, the samples were washed and treated with $0.1 \%$ cacodylate buffered tannic acid, post -fixed with $1 \%$ buffered osmium tetroxide for $30 \mathrm{~min}$, and stained with $1 \%$ uranyl acetate. The samples were dehydrated in increasing concentrations of ethanol, infiltrated, and embedded in Poly-bed 812 medium. The samples were polymerized in a $60^{\circ} \mathrm{C}$ oven for 2 days. For both cell and S1MP samples, ultrathin sections were cut in Leica Ultracut microtome (Leica, Deerfield, IL), stained with uranyl acetate and lead citrate in a Leica EM Stainer, and examined in a JEM 1010 transmission electron microscope (TEM) (JOEL, USA, Inc., Peabody, MA) at an accelerating voltage of $80 \mathrm{kV}$. Digital images were obtained using the AMT Imaging System (Advanced Microscopy Techniques, Danvers, MA).

\subsection{Antibody conjugation}

Anti-PECAM antibody was obtained from Sigma, while anti-VEGF R2/KDR (vascular endothelial growth factor receptor) and isotype control $\left(\mathrm{IgG}_{1}\right)$ fluorescein conjugated antibodies were purchased from R\&D Systems (Minneapolis, MN). Antibodies were covalently attached to APTES capped/loaded S1MPs (i.e. MDS) according to the Pierce Biotechnology (Thermo Scientific Inc., Rockford, IL) manufacturer's protocol entitled, "EDC/NHS Crosslinking of Carboxylates and Primary Amines". For the conjugation, each reaction contained $5 \times 10^{6} \mathrm{~S} 1 \mathrm{MPs}$ and $10 \mu \mathrm{g}$ of antibody in a final volume of $250 \mu \mathrm{l}$.

\subsection{Flow cytometry}

HMVECs, a kind gift from Rong Shao at Baystate Medical Center/University of Massachusetts, were cultured in Clonetics ${ }^{\circledR}$ EGM® Endothelial Cell Growth Medium (Lonza; Walkersville, MD), while HUVECs were purchased from Lonza Walkersville, Inc. and maintained in EBM ${ }^{\circledR}-2$ medium (Clonetics $\left.{ }^{\circledR}\right)$. HUVECs or HMVECs $\left(1.5 \times 10^{5}\right.$ cells/ well) were seeded into 6 well plates and 24 hours later the cells were incubated with the $4 \times$ $10^{6}$ silicon microparticles/well in complete media for 60 minutes. Microparticle association with cells was determined by measuring side scatter increase using a Becton Dickinson 
FACSCalibur Flow Cytometer equipped with a 488-nm argon laser and CellQuest software (Becton Dickinson; San Jose, CA).

\subsection{Confocal microscopy}

HUVECs were grown on No.1.5 glass cover slips. When $80 \%$ confluent, cells were incubated with loaded and capped antibody-conjugated S1MPs (1:10; cell: S1MP) for 120 minutes in complete media at $37^{\circ} \mathrm{C}$. Cells were then washed with PBS, fixed with $4 \%$ formaldehyde and permeabilized with $0.1 \%$ Triton $\mathrm{x}-100$. PBS containing $1 \%$ BSA was used as a blocking agent prior to incubation with $200 \mathrm{nM}$ Rhodamine conjugated phalloidin (Invitrogen; Carlsbad, CA) and $2 \mu \mathrm{l} / \mathrm{ml}$ DRAQ5 (Biostatus Limited, UK) for 20 minutes. Coverslips were then washed and mounted on glass slides using Prolong Gold Antifade Reagent (Invitrogen). Images were acquired using a Leica DM6000 upright confocal microscope equipped with a $63 \times$ oil immersion objective.

Quantitation of antibody conjugated to the MDS was determined using a Becton Dickinson FACSCalibur Flow Cytometer equipped with a 488-nm argon laser and CellQuest software (Becton Dickinson; San Jose, CA). Antigen density calculations were based on a QuickCal ${ }^{\circledR}$ calibration curve generated with Quantum ${ }^{\mathrm{TM}}$ Simply Cellular® anti-Mouse IgG (Bangs Laboratories, Inc.; Fishers, IN).

\subsection{Animal studies}

Crl:NU-Foxn $1^{n u}$ mice (Charles Rivers Laboratories International, Inc., Wilmington, MA) were administered either $1 \times 10^{8}$ control S1MPs or SPION loaded and capped S1MPs via tail vein in $100 \mu \mathrm{l}$ PBS. At either 2 or 24 hours post injection tissues were harvested, fixed in $10 \%$ formalin, and embedded in paraffin. Lung, spleen, and liver sections were deparaffinized and stained with Prussian Blue and Nuclear Fast Red [37]. Briefly, tissues were deparaffinized in S3.Histo (BBC Biochemical) for 10 minutes, hydrated in decreasing solutions of aqueous ethanol, and stained with equal parts of $20 \%(\mathrm{v} / \mathrm{v})$ hydrochloric acid and of $10 \%(\mathrm{v} / \mathrm{v})$ potassium ferrocyanide (Sigma-Alrich) for 20 minutes. Slides were then counterstained with Nuclear Fast Red (Sigma-Aldrich), and then dehydrated and cleared with S3·Histo.

\subsection{MTT cell proliferation assay}

J774A. 1 cells were seeded into 96 well plates at 5000 cells/well in a final volume of $200 \mu 1 /$ well complete media. 24 hours later, media $(0.5 \mathrm{ml})$ containing oxidized S1MPs, either unloaded or loaded (electrostatic or capped) with SPIONs (10:1, S1MPs:cells) were added. After $24,48,72$, and 96 hours at $37^{\circ} \mathrm{C}$, media was removed and fresh media containing 0.5 $\mathrm{mg} / \mathrm{mL}$ 3-(4,5-dimethylthiazol-2-yl)-2,5-diphenyltetrazolium bromide (MTT; Sigma) was added at $200 \mu \mathrm{l} / \mathrm{well}$ for $4 \mathrm{hrs}$ at $37^{\circ} \mathrm{C}$. The media was then replaced with dimethyl sulfoxide $(180 \mu \mathrm{l} /$ well). After $30 \mathrm{~min}$ at room temperature, absorbance was read at $570 \mathrm{~nm}$ using a SPECTRA max M2 plate reader (Molecular Devices).

\subsection{Degradation studies}

SPION-loaded S1MPs $\left(1-5 \times 10^{6}\right)$, with and without the APTES cap, were suspended in PBS or fetal bovine serum in microfuge tubes and rotated for up to 24 hours at $25^{\circ} \mathrm{C}$ or $37^{\circ} \mathrm{C}$ using a Barnstead Thermodyne Labquake Rotator. At the indicated time points, S1MPs were either centrifuged or filtered $(0.45 \mu \mathrm{m})$ to collect microparticles, and the supernatant and particle pellet were analyzed for iron and silicon content by Inductively Coupled Plasma Optical Emission Spectroscopy (ICP-OES) using a Varian Vista AX set at $1 \mathrm{~kW}$, with plasma flow set to $15 \mathrm{~L} / \mathrm{min}$, auxiliary flow of $1.5 \mathrm{~L} / \mathrm{min}$ and a nebulizer flow of $0.75 \mathrm{~L} / \mathrm{min}$. 


\subsection{Data analysis}

Data is presented as means and standard deviations, with at least 3 data points per group. For statistical comparisons a Student's $t$ test was performed (two-tailed distribution, two-sample equal variance).

\section{Supplementary Material}

Refer to Web version on PubMed Central for supplementary material.

\section{Acknowledgments}

We thank Hitachi for training and use of the Hitachi S-5500 SEM. We wish to thank Kenneth Dunner Jr. for TEM analysis (Figures $2 \& 3$ ) at the High Resolution Imaging Facility at the University of Texas MD Anderson Cancer Center (MDACC). In the Department of Nanomedicine and Biomedical Engineering at University of Texas Health Science Center we thank Sarah Amra for tissue processing and histological staining of specimens, and we thank Qingpo Li for particle injections in mice and tissue collection. We wish to thank the ICMB and the MRC at the University of Texas at Austin for use of instrumentation and facilities. We thank Dwight Romanovicz and Hugo Celio at the University of Texas at Austin for help with STEM sample preparation and analysis, and Matt Landry for drawings used in the graphical abstract. This research was supported by the Department of Defense, grants DODW81XWH-07-1-0596, DODW81XWH-09-1-0212 and DODW81XWH-07-2-0101; NASA NNJ06HE06A; NIH RO1CA128797; MDACC Institutional Core Grant \#CA-016672; and State of Texas, Emerging Technology Fund.

\section{References}

1. Giotta F, Lorusso V, Maiello E, Filippelli G, Valerio MR, Caruso M, Verderame F, Latorre A, Colucci G. Ann Oncol 2007;18 6:vi66-69. [PubMed: 17591836]

2. Treat J, Greenspan A, Forst D, Sanchez JA, Ferrans VJ, Potkul LA, Woolley PV, Rahman A. J Natl Cancer Inst 1990;82(21):1706-1710. [PubMed: 2231759]

3. Rahman A, Treat J, Roh JK, Potkul LA, Alvord WG, Forst D, Woolley PV. J Clin Oncol 1990;8(6): 1093-1100. [PubMed: 2348224]

4. Stinchcombe TE, Socinski MA, Lee CB, Hayes DN, Moore DT, Goldberg RM, Dees EC. J Thorac Oncol 2008;3(5):521-526. [PubMed: 18449006]

5. Tasciotti E, Liu X, Bhavane R, Plant K, Leonard AD, Price BK, Cheng MM, Decuzzi P, Tour JM, Robertson F, Ferrari M. Nat Nanotechnol 2008;3(3):151-157. [PubMed: 18654487]

6. Chiappini C, Tasciotti E, Fakhoury JR, Fine D, Pullan L, Wang YC, Fu L, Liu X, Ferrari M. Chemphyschem. 2010

7. Serda RE, Gu J, Bhavane RC, Liu X, Chiappini C, Decuzzi P, Ferrari M. Biomaterials 2009;30(13): 2440-2448. [PubMed: 19215978]

8. Decuzzi P, Ferrari M. Biomaterials 2008;29(3):377-384. [PubMed: 17936897]

9. Decuzzi P, Lee S, Bhushan B, Ferrari M. Ann Biomed Eng 2005;33(2):179-190. [PubMed: 15771271]

10. Decuzzi P, Pasqualini R, Arap W, Ferrari M. Pharm Res 2009;26(1):235-243. [PubMed: 18712584]

11. E H, Anderson HC, Wallis DJ, Canham LT, Powell JJ. Phys Stat Sol (a) 2003;197:331-335.

12. R C, Canham LT, Newey JP, Houlton MR, Cox TI, et al. Adv Mater 1999;11:1505-1507.

13. Smith JW, Cheresh DA. J Biol Chem 1990;265(4):2168-2172. [PubMed: 1688848]

14. Serda RE, Adolphi NL, Bisoffi M, Sillerud LO. Mol Imaging 2007;6(4):277-288. [PubMed: 17711783]

15. Yang X, Wang H, Beasley DW, Volk DE, Zhao X, Luxon BA, Lomas LO, Herzog NK, Aronson JF, Barrett AD, Leary JF, Gorenstein DG. Ann N Y Acad Sci 2006;1082:116-119. [PubMed: 17145932]

16. Dorvee JR, Sailor MJ, Miskelly GM. Dalton Trans 2008;(6):721-730. [PubMed: 18239825]

17. Thomas JC, Pacholski C, Sailor MJ. Lab Chip 2006;6(6):782-787. [PubMed: 16738731] 
18. Weissleder R, Hahn PF, Stark DD, Rummeny E, Saini S, Wittenberg J, Ferrucci JT. AJR Am J Roentgenol 1987;149(4):723-726. [PubMed: 3498320]

19. Bacon BR, Stark DD, Park CH, Saini S, Groman EV, Hahn PF, Compton CC, Ferrucci JT Jr. J Lab Clin Med 1987;110(2):164-171. [PubMed: 3598345]

20. Weissleder R, Stark DD, Engelstad BL, Bacon BR, Compton CC, White DL, Jacobs P, Lewis J. AJR Am J Roentgenol 1989;152(1):167-173. [PubMed: 2783272]

21. Reimer P, Balzer T. Eur Radiol 2003;13(6):1266-1276. [PubMed: 12764641]

22. Gabizon A, Shmeeda H, Horowitz AT, Zalipsky S. Adv Drug Deliv Rev 2004;56(8):1177-1192. [PubMed: 15094214]

23. Gu F, Zhang L, Teply BA, Mann N, Wang A, Radovic-Moreno AF, Langer R, Farokhzad OC. Proc Natl Acad Sci U S A 2008;105(7):2586-2591. [PubMed: 18272481]

24. Decuzzi P, Ferrari M. Biophys J 2008;94(10):3790-3797. [PubMed: 18234813]

25. Swirski FK, Nahrendorf M, Etzrodt M, Wildgruber M, Cortez-Retamozo V, Panizzi P, Figueiredo JL, Kohler RH, Chudnovskiy A, Waterman P, Aikawa E, Mempel TR, Libby P, Weissleder R, Pittet MJ. Science 2009;325(5940):612-616. [PubMed: 19644120]

26. Manolova V, Flace A, Bauer M, Schwarz K, Saudan P, Bachmann MF. Eur J Immunol 2008;38(5): 1404-1413. [PubMed: 18389478]

27. Beduneau A, Ma Z, Grotepas CB, Kabanov A, Rabinow BE, Gong N, Mosley RL, Dou H, Boska MD, Gendelman HE. PLoS ONE 2009;4(2):e4343. [PubMed: 19183814]

28. Liu W, Frank JA. Eur J Radiol 2009;70(2):258-264. [PubMed: 18995978]

29. Falguieres T, Luyet PP, Gruenberg J. Exp Cell Res 2009;315(9):1567-1573. [PubMed: 19133258]

30. Arkles B. Paint \& Coatings Industry. 2006

31. Fiorilli S, Rivlo P, Ricciardi C, Pasquardini L, Lunelli L, Vanzetti L, Pederzolli C, Onida B, Garrone E. Journal of Colloid and Interface Science 2008;321:235-241. [PubMed: 18258249]

32. Serda RE, Ferrati S, Godin B, Tasciotti E, Liu X, Ferrari M. Nanoscale 2009;1(2):250-259. [PubMed: 20644846]

33. Decuzzi P, Godin B, Tanaka T, Lee SY, Chiappini C, Liu X, Ferrari M. J Control Release. 2009

34. Zhang X, Zhang C, Guo H, Huang W, Polenova T, Francesconi LC, Akins DL. J Phys Chem B 2005;109(41):19156-19160. [PubMed: 16853470]

35. Boujday S, Blanchard J, Villanneau R, Krafft JM, Geantet C, Louis C, Breysse M, Proust A. Chemphyschem 2007;8(18):2636-2642. [PubMed: 18058778]

36. Mellaerts R, Jammaer JA, Van Speybroeck M, Chen H, Van Humbeeck J, Augustijns P, Van den Mooter G, Martens JA. Langmuir 2008;24(16):8651-8659. [PubMed: 18630936]

37. Gupta AK, Gupta M. Biomaterials 2005;26(13):1565-1573. [PubMed: 15522758]

\section{Abbreviations}

$\begin{array}{ll}\text { MDS } & \text { multi-stage delivery system } \\ \text { S1MP } & \text { stage 1 mesoporous silicon microparticle } \\ \text { SPION } & \text { superparamagnetic iron oxide nanoparticle } \\ \text { APTES } & \text { 3-aminopropyltriethoxysilane } \\ \text { IO } & \text { SPION }\end{array}$



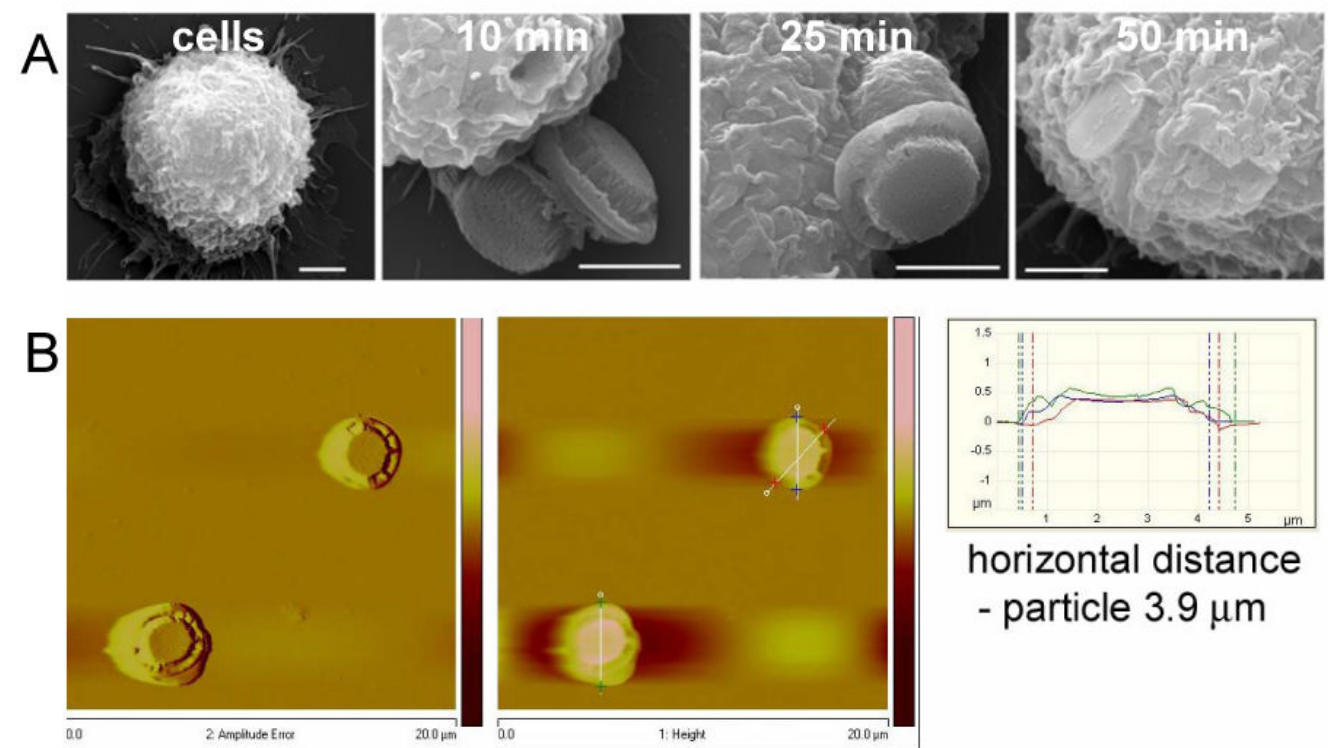

horizontal distance

- particle $3.9 \mu \mathrm{m}$
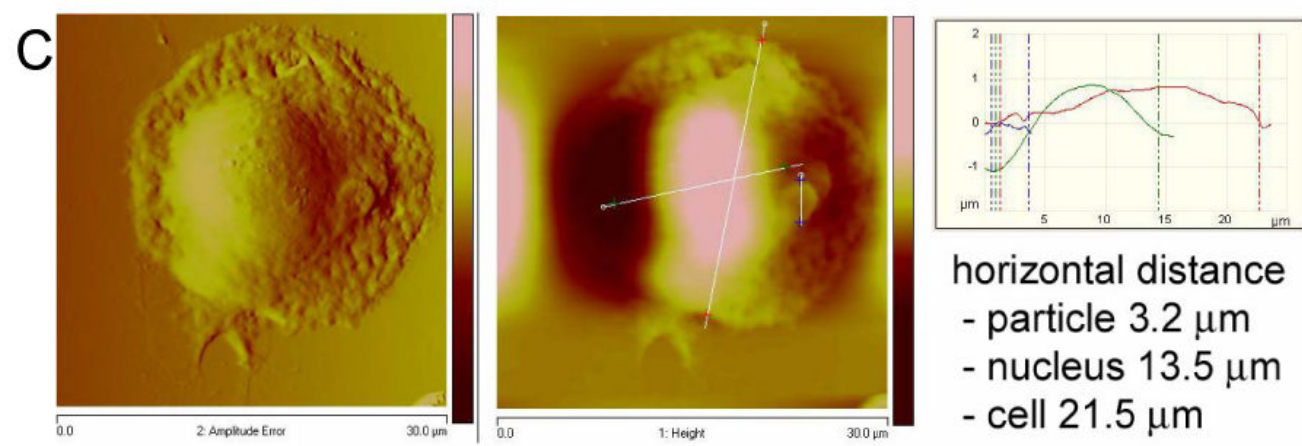

Figure 1. Cellular engulfment of S1MPs by J774A.1 macrophages

A) SEM images of J444A.1 cells incubated with S1MPs (at a ratio of 1:5) for different lengths of time demonstrating particle orientation during uptake and varying degrees of internalization (10k, 50k, 50k, 40k; bars $2 \mu \mathrm{m}$ ). B) AFM amplitude and height images, including section analysis demonstrating height and diameter of S1MPs. C) AFM image and section analysis of a J774A.1 cell following internalization of S1MPs (1:5 ratio). 


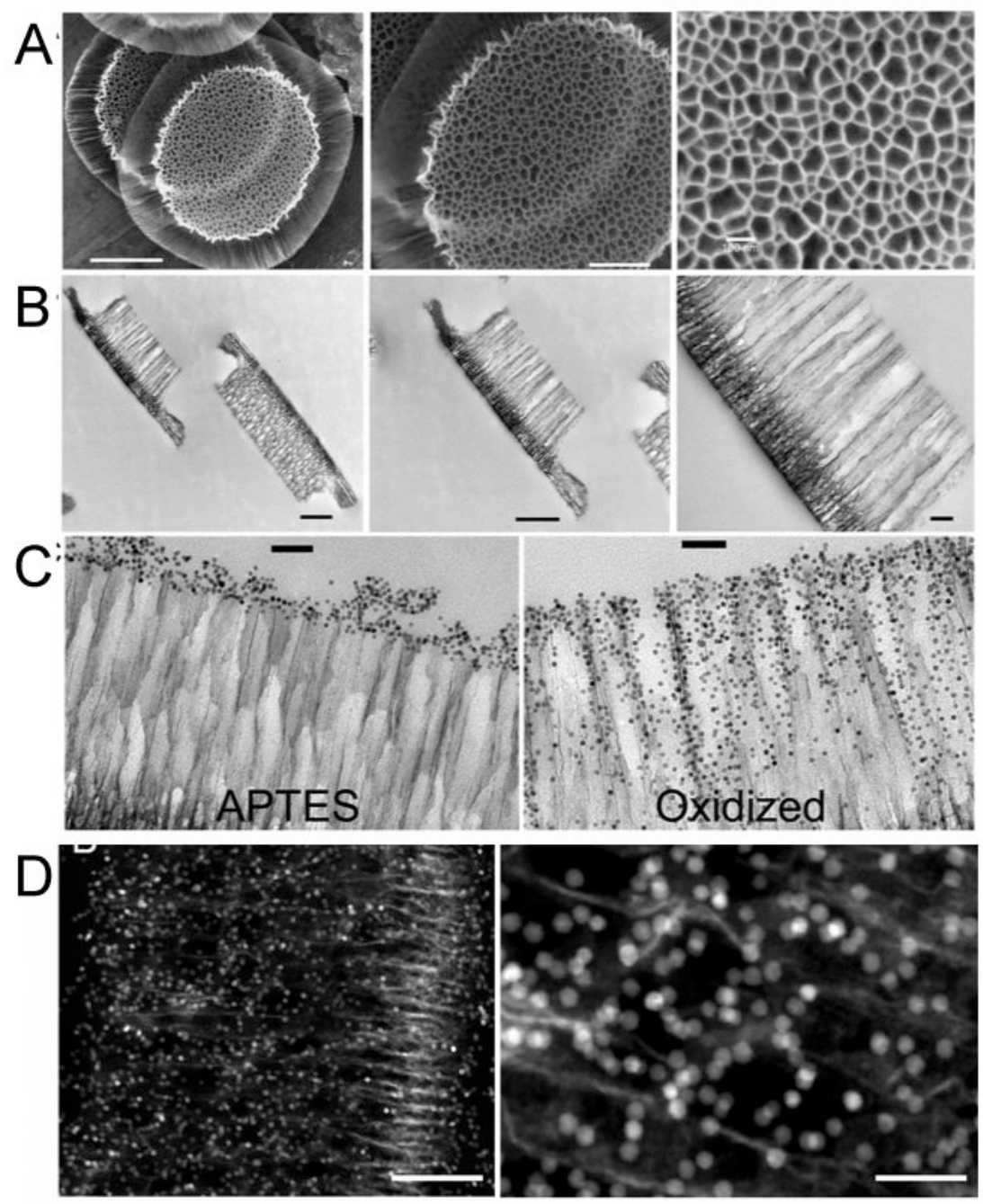

Figure 2. Discoidal S1MP loading with SPIONs

A) SEM micrographs of S1MPs taken at increasing magnification (35k, 60k, 150k; bar $1000,500,100 \mathrm{~nm}$ ). B) TEM micrographs of ultrathin sections of resin-embedded S1MPs taken at increasing magnification (30k, 40k, 100k; bar $500 \mathrm{~nm}, 500 \mathrm{~nm}, 100 \mathrm{~nm})$. C) TEM images of ultrathin sections of S1MPs loaded with SPIONs following surface modification of the S1MPs by either oxidation or by oxidation and subsequent APTES (9\%) modification $(100 \mathrm{k}$, bar $100 \mathrm{~nm})$. D) HAADF-STEM micrographs showing the porous matrix of an oxidized S1MP loaded with SPIONs (bar $200 \mathrm{~nm}$ (left), $50 \mathrm{~nm}$ (right)). 

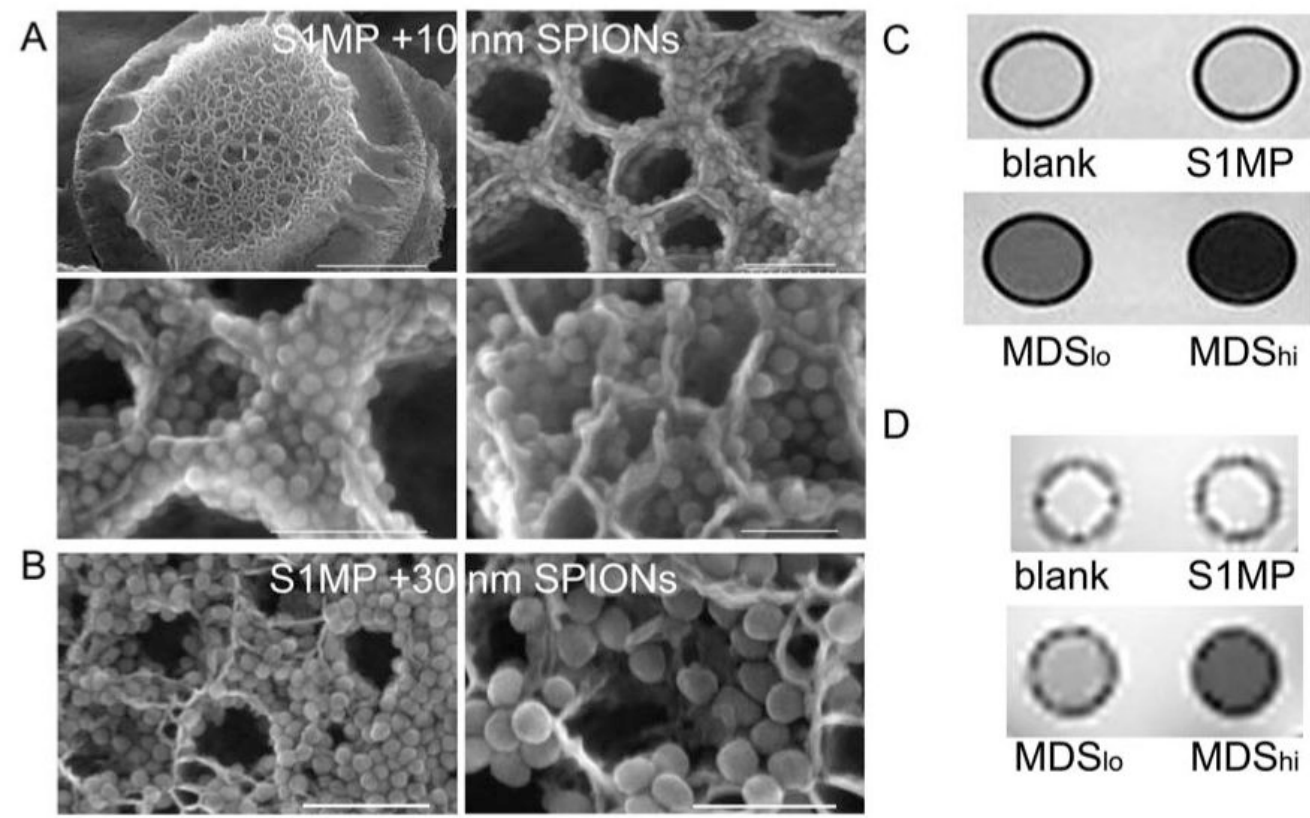

MDS।

Figure 3. High resolution SEM and MR imaging

S1MPs loaded with SPIONs at increasing magnifications. A) S1MP loaded with $10 \mathrm{~nm}$ SPIONs (25k, 300k, 500k, 600k; bar $1 \mu \mathrm{m}, 100 \mathrm{~nm}, 100 \mathrm{~nm}, 50 \mathrm{~nm}$ ). B) S1MP loaded with $30 \mathrm{~nm}$ SPIONs (200k, 450k; bar $200 \mathrm{~nm}, 100 \mathrm{~nm}$ ). C-D) Axial spin- (C) and gradient- (D) echo MR images of NMR tubes containing PBS (blank), S1MPS, and MDS loaded with low $\left(\mathrm{MDS}_{\mathrm{lo}}\right)$ or high $\left(\mathrm{MDS}_{\mathrm{hi}}\right)$ levels of SPIONs. 

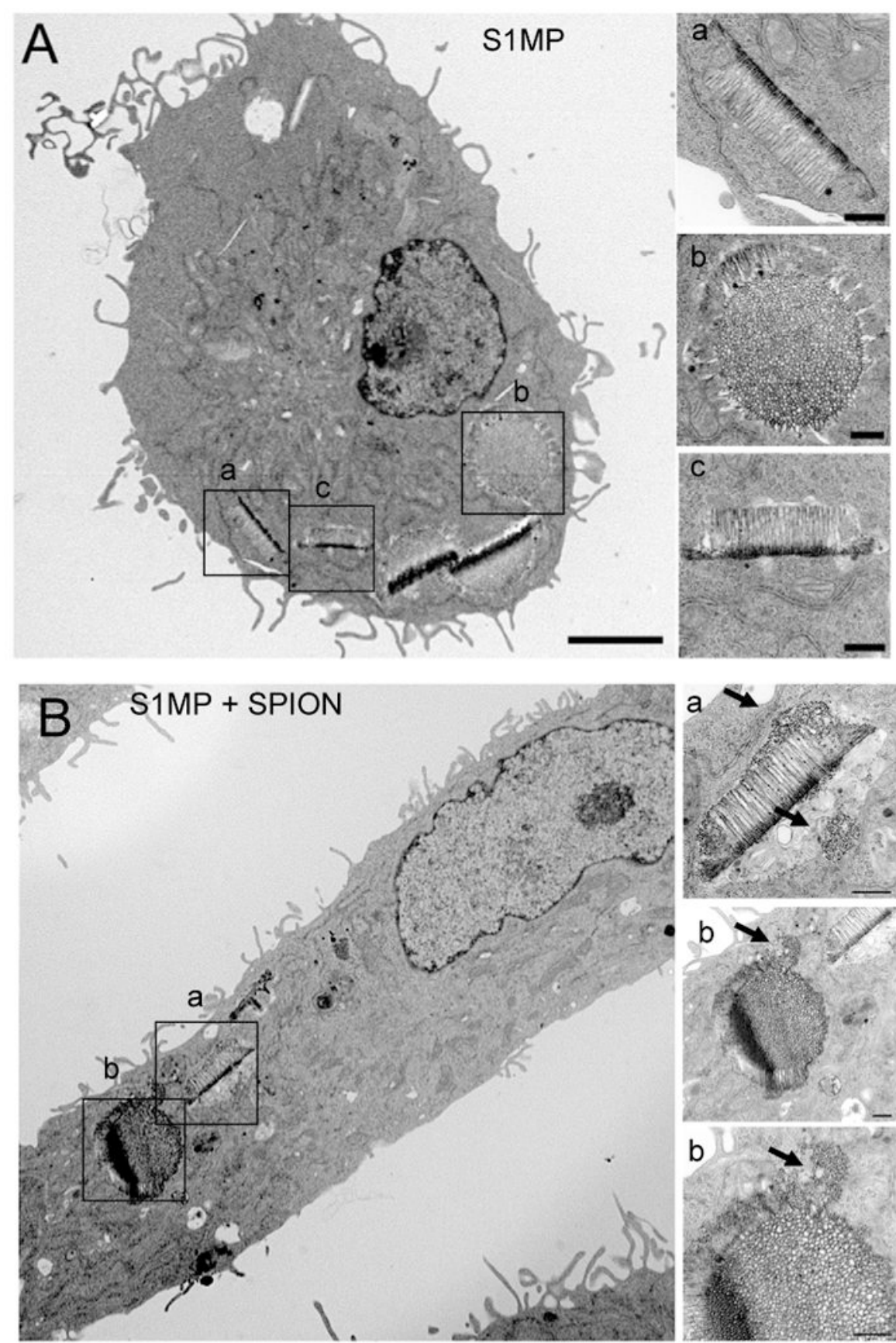

Figure 4. Intracellular trafficking of the MDS

Transmission electron micrographs of ultrathin sections of J774A.1 cells 24 hours after introduction of either control (A) or SPION loaded (B) S1MPs (at a ratio of 1:5). Cells are shown to the left at $6 \mathrm{k}$ magnification (bar $3 \mu \mathrm{m}$ ) and to the right at $25 \mathrm{k}$ and $50 \mathrm{k}$ magnification (bars $500 \mathrm{~nm}$ ). Internalized S1MPs can be seen in different orientations, with clusters of SPIONs indicated by black arrows. 

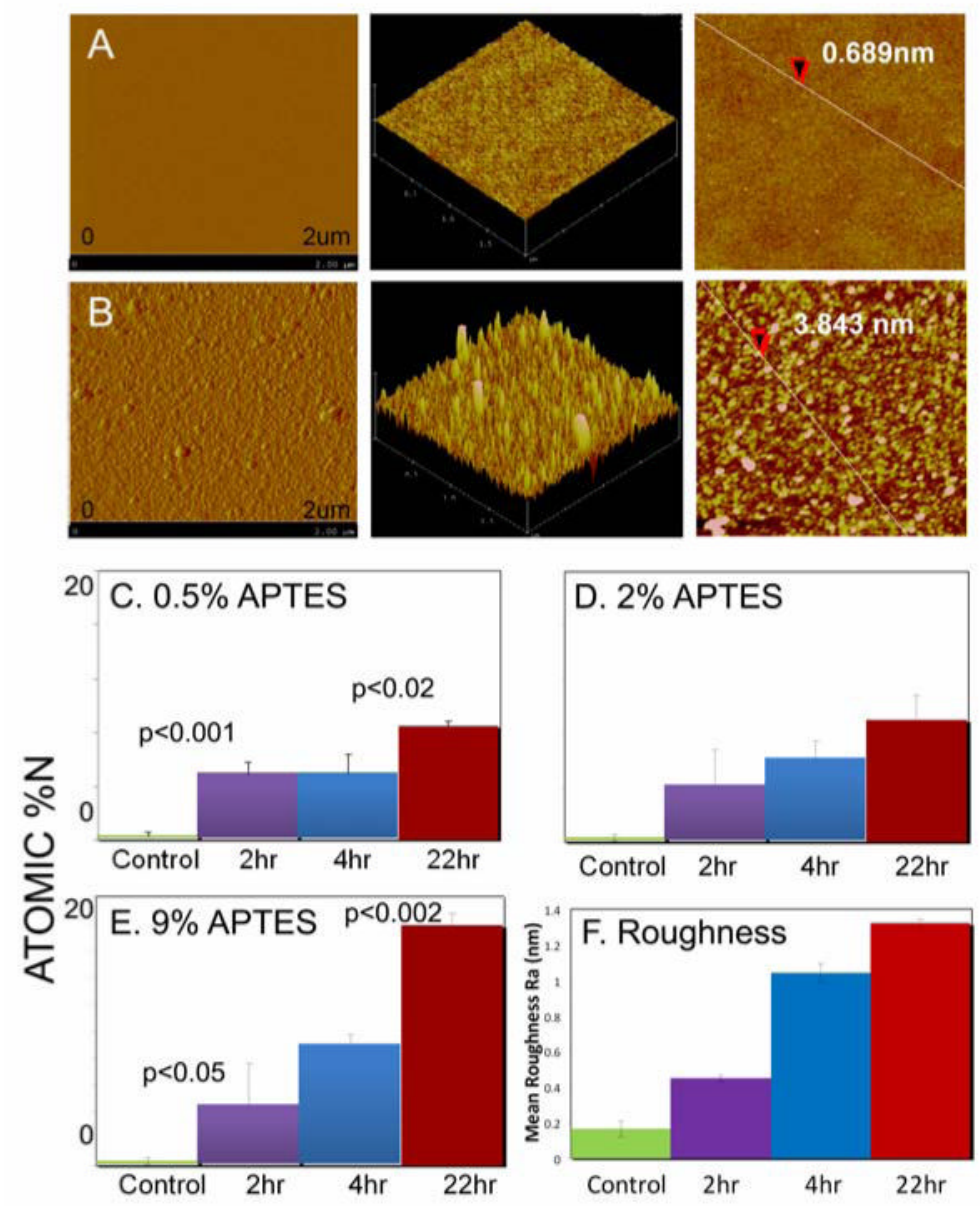

Figure 5. Surface height and roughness of chemically modified porous silicon A,B) AFM images of amplitude, 3D structure, and height of oxidized (A) and APTES modified (B) (0.5\% for 4 hours) porous silicon. C-E) XPS analysis of atomic $\%$ nitrogen on the porous silicon surface was determined at various time points for APTES polymerization using $0.5 \%(\mathrm{C}), 2 \%(\mathrm{D})$, and $9 \%(\mathrm{E})(\mathrm{v} / \mathrm{v})$ solution of APTES. F) Surface roughness is presented at each time point for porous silicon modified with $0.5 \%$ APTES. 

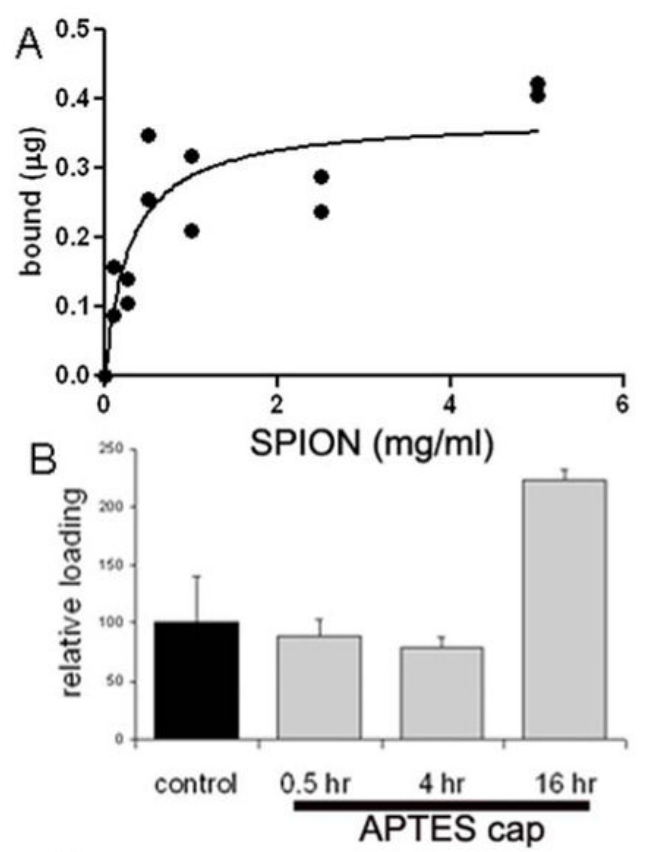

C
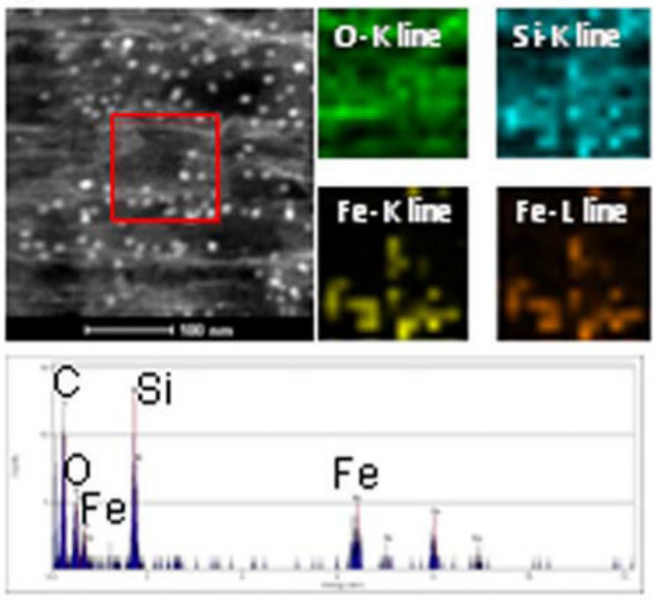

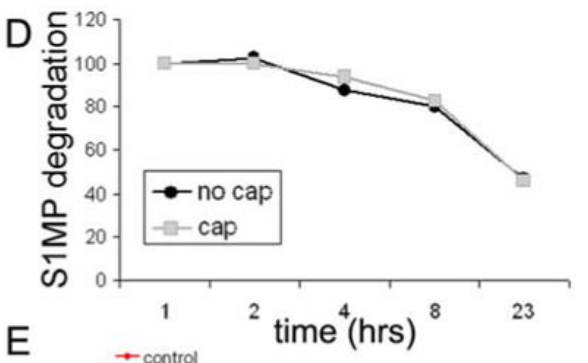

E
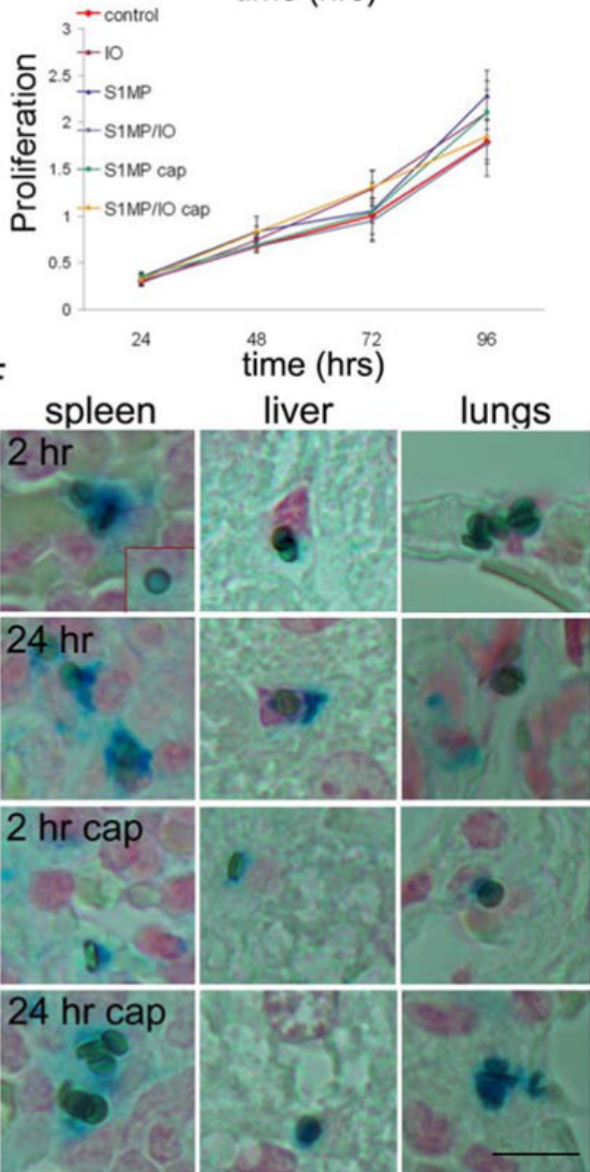

Figure 6. Loading and retention of SPIONs in S1MPs

A) Loading curve for S1MPs loaded with SPIONs. Iron load was based on Prussian blue analysis of the loaded S1MPs. B) Effect of APTES "capping" on loading with SPIONs C) EDX elemental mapping confirming the presence of SPIONs in the porous silicon matrix following capping with APTES (left, the red box indicates the area of the HAADF-STEM image analyzed by EDX). Intensity maps for relevant elements present in the sample are presented. Bottom row: typical EDX spectrum. D) Degradation of SPION loaded S1MPs in PBS at $37^{\circ} \mathrm{C}$ with time. E) MTT proliferation assay of J774A.1 cells incubated with SPIONs (IO), S1MPs (oxidized or APTES capped, or MDS (S1MP/IO). F) Prussian blue staining of lung, spleen and liver harvested from mice at 2 and 24 hours after injection of $1 \times 10^{8}$ MDS, capped or un-capped (bar $10 \mu \mathrm{m}$ ). 

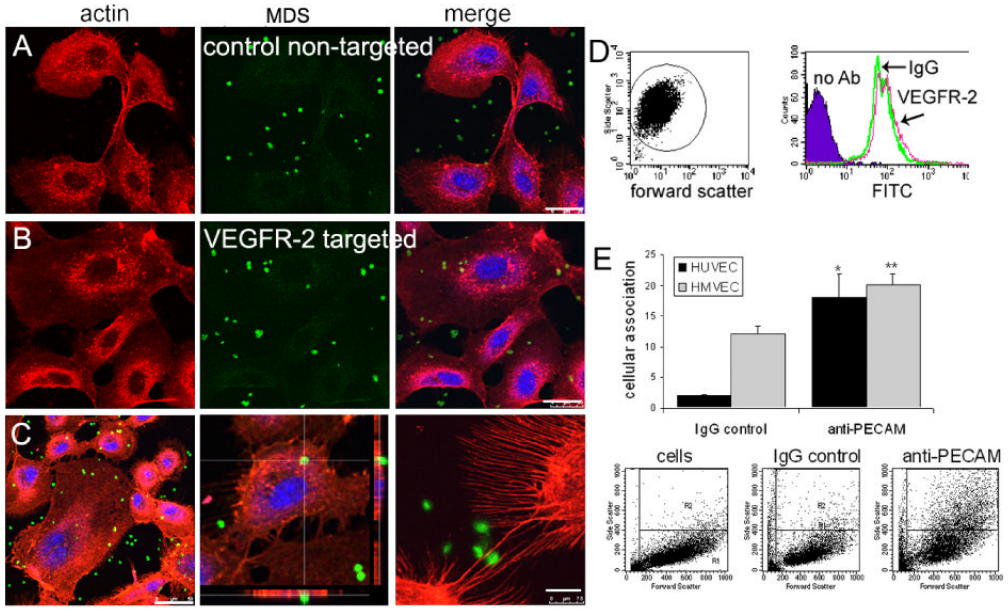

Figure 7. Endothelial targeting with the assembled MDS

A) HUVECs were incubated with either control IgG fluorescein labeled MDS (A) or antiVEGFR-2 fluorescein antibody labeled MDS (B,C) for 2 hours at $37^{\circ} \mathrm{C}(10: 1$ ratio of particles to cells). C) Antibody-targeted cells are shown at two magnifications, with 3D images at the crosshairs of the higher magnification image (middle). To the right, lamellopodia projecting from two cells make contact with the MDS [63× oil immersion lens; (A,B) bar $25 \mu \mathrm{m},(\mathrm{C})$ bar 50 and $7.5 \mu \mathrm{m}$, respectively; actin: rhodamine phalloidin; nuclei: DRAQ5]. D) A flow cytometry dot plot (left) showing microparticle light scatter and a histogram (right) showing microparticle fluorescence before and after conjugation with fluorescent antibody. E) Bar graph (top) showing relative association of the MDS with HUVEC and HMVEC endothelial cells conjugated with either control IgG or anti-PECAM specific antibody. Below are representative flow cytometry dot plots showing the increase in side scatter in HUVECs after incubation with targeted (anti-PECAM) MDS. 


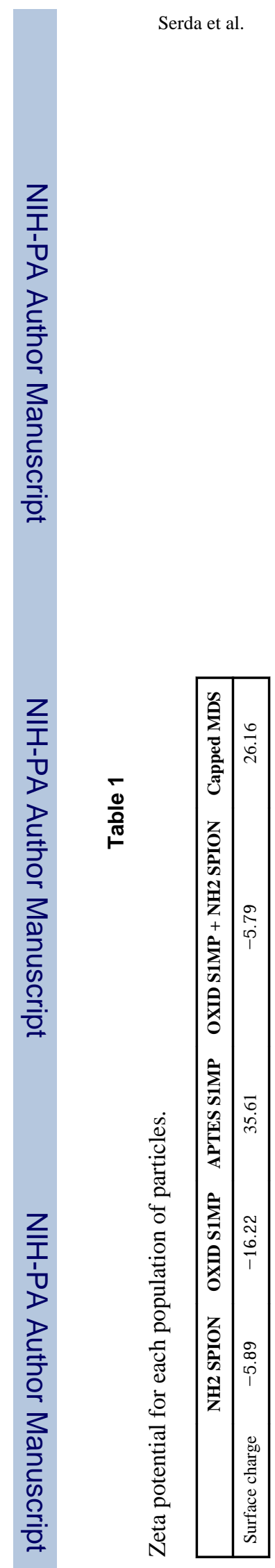

Small. Author manuscript; available in PMC 2011 June 21. 